\title{
La intervención en la actualidad
}

\section{The intervention at present}

\author{
Gerardo M. Perdigón-Castañeda*
}

Expresidente de la Sociedad Mexicana de Radiología e Imagen, A.C., México

Los avances en el campo de la radiología, como la técnica de Seldinger, junto con la innovación del instrumental, permitieron el desarrollo de los procedimientos intervencionistas en los años 1970, y se vio que los procedimientos vasculares tenían mejor respuesta con la mínima intervención.

Los radiólogos intervencionistas fueron pioneros en la medicina moderna con el cateterismo y la angioplastia, que fue realizada por primera vez por el Dr. Charles Dotter, aunque no usó balones, sino dilatadores. El Dr. Dotter, radiólogo intervencionista, es conocido como el padre de la radiología intervencionista por ser el pionero en utilizar esta técnica, por lo que fue nominado para el Premio Nobel de Fisiología y Medicina en 1978.

El Dr. Alejandro Margulis acuñó el término «intervención» para estas nuevas técnicas mínimamente invasivas.
Lo que llamamos radiología intervencionista ha ido evolucionando desde la década de 1980 en todo el mundo para desarrollar diferentes técnicas de abordaje quirúrgico que han demostrado ser igual de eficaces que la cirugía convencional. A ello ha contribuido el conocimiento de imágenes, medios de contraste y técnicas quirúrgicas con los equipos de imagen de alta resolución, que han mejorado la imagen de forma importante y permiten realizar procedimientos dirigidos con los diferentes equipos de un modo seguro. Estas intervenciones se han divido en procedimientos de radiología intervencionista diagnósticos, vasculares y no vasculares.

Con el tiempo se ha constatado la eficacia de los procedimientos de radiología intervencionista, a pesar de las críticas y las dudas iniciales. Han demostrado, en ciertas patologías, ser el tratamiento de primera elección, y han permitido realizar procedimientos diagnósticos, 
paliativos y preparativos que son de gran ayuda para cirujanos y clínicos.

Estos procedimientos son económicos, rápidos, efectivos y seguros, realizados por médicos radiólogos entrenados que han evolucionado año con año, mejorándolos y llevando a cabo nuevos procedimientos, debido a la mejora de la tecnología, con lo que se han vuelto indispensables como armamento terapéutico en las diferentes disciplinas de la medicina.

La interrelación del radiólogo y las diferentes especialidades clínicas y quirúrgicas debe tomarse en cuenta para el bien del paciente, que es nuestra prioridad. 